\title{
Biomechanical comparison of pullout strengths of six pedicle screws with different thread designs
}

\author{
Ahmet Karakaşlı, $\mathrm{MD}^{1}\left(\mathbb{D}\right.$, Nihat Acar, $\mathrm{MD}^{2}$ (D) R. Buğra Hüsemoğlu, $\mathrm{PhD}^{3}$ (D) \\ 'Department of Orthopedics and Traumatology, Dokuz Eylül University, Faculty of Medicine, Izmir, Turkey \\ ${ }^{2}$ Department of Orthopedics and Traumatology, Çatalca Ilyas Çokay Hospital, Istanbul, Turkey \\ ${ }^{3}$ Department of Biomechanics, Dokuz Eylül University, Faculty of Medicine, Izmir, Turkey
}

Osteoporosis is a very common disease which causes a remarkable decrease in the whole bone mass and an increase in the incidence of bone fractures. ${ }^{[1]}$ Osteoporosis-related vertebral fractures are responsible for 42 to $48 \%$ of the variation in kyphosis in the general population. ${ }^{[2]}$ Hardware pullout is one of the main complications frequently encountered in spine fixation of the osteoporotic bone. It is mainly associated with the weak characteristic of the architecture of bone, which can be often the result of either micro-motion or the excessive force applied at the bone-metal boundary ${ }^{[3]}$ Excessive osteoporosis can be sometimes considered a contraindication for spinal fixation in compression fractures; however, in many cases such as spinal instability, tumors and unstable burst fractures, transpedicular screw fixation can be the only available surgical option to offer spinal stabilization. ${ }^{[4-6]}$

Received: June 09, 2020

Accepted: November 12, 2020

Published online: January 06, 2021

Correspondence: Ahmet Karakașlı, MD. Dokuz Eylül Üniversitesi Tıp Fakültesi Ortopedi ve Travmatoloji Anabilim Dalı, 35340 İnciraltı, İzmir, Türkiye.

E-mail: karakasliahmet@gmail.com

Doi: $10.5606 /$ ehc. 2021.77004

Citation: Karakașlı A, Acar N, Hüsemoğlu RB. Biomechanical comparison of pullout strengths of six pedicle screws with different thread designs. Jt Dis Relat Surg 2021;32(1):192-197.

(C2021 All right reserved by the Turkish Joint Diseases Foundation

This is an open access article under the terms of the Creative Commons Attribution-NonCommercial License, which permits use, distribution and reproduction in any medium, provided the original work is properly cited and is not used for commercial purposes (http://creativecommons.org/licenses/by-nc/4.0/).

\section{ABSTRACT}

Objectives: This study aims to assess the pullout strength of six different pedicle screw thread patterns.

Materials and methods: A total of 36 sheep spines were divided into six groups including six spines in each group: fully threaded cortical (Type A), fully threaded spongeous (Type B), fully cortical threads in the proximal half and fully spongeous threads in the distal half (Type C), fully spongeous threads in the proximal half and fully cortical threads in the distal half (Type D), unthreaded proximal half with fully spongeous threads in the distal half (Type E), and unthreaded proximal half with fully cortical threads in the distal half (Type F). The axial compression-traction machine was used for biomechanical testing at a pullout rate of $1 \mathrm{~mm} / \mathrm{min}$.

Results: The mean values of pullout strength of the groups A, $\mathrm{B}, \mathrm{C}, \mathrm{D}, \mathrm{E}$, and F were $1112 \pm 7.52 \mathrm{~N}, 986 \pm 8.34 \mathrm{~N}, 646 \pm 3.88 \mathrm{~N}$, $676 \pm 7.16 \mathrm{~N}, 609 \pm 9.52 \mathrm{~N}$, and $769 \pm 6.49 \mathrm{~N}$, respectively. There was a statistically significant difference between the screw groups $\mathrm{A}$ and $\mathrm{B}, \mathrm{C}, \mathrm{D}, \mathrm{E}$ and $\mathrm{F}$ ( $\mathrm{p}=0.036, \mathrm{p}=0.028, \mathrm{p}=0.04, \mathrm{p}=0.039$, and $\mathrm{p}=0.046$, respectively). A statistically significant difference was observed between the groups $B$ versus $C$ and $E(p=0.037$ and $p=0.021$, respectively). There was no statistically significant difference between the groups $B$ versus $D$ and $F(p=0.35$ and $\mathrm{p}=0.61$, respectively).

Conclusion: Fully threaded cortical pedicular screw design exhibited the strongest bone grasp compared to other thread designs. Further studies should be conducted in multidirectional force pattern on human spine to assess the six screw thread designs in a closer real-life setting simulation model.

Keywords: Spine, pullout strength, screw thread design.

In the literature, the first screw placed through the lateral articulation to stabilize the lumbar spine was utilized by Dr. King. ${ }^{[6]}$ Boucher, ${ }^{[7]}$ in the late 1950s, attempted using long transpedicular screws which was modified later on by the addition of a rod system in an attempt to fuse multiple spinal segments together. Since then, this transpedicular screw rod system has become the gold standard technique for vertebral surgery. 
Despite the modern advancement of vertebral surgery, stable screw fixation through a compromised bone quality is still a concern. ${ }^{[8-13]}$ To date, many studies have been conducted, both clinically and in laboratory settings, in an attempt to increase the amount of screw fixation strength in osteoporotic bone. Different methods such as augmenting the screw with hydroxyapatite, polymethylmethacrylate and calcium phosphate have been demonstrated to increase the purchase of screws in osteoporotic bone. ${ }^{[10-13]}$ Screw design alteration is another method which has been researched by several authors to enhance transpedicular screw pullout strength in a low-quality osteoporotic bone. ${ }^{[14,15]}$ Many factors including screw diameter, length, inner diameter tapering and thread design have been demonstrated to influence the pullout strength of a transpedicular screw. Different thread designs including fully threaded cortical, fully threaded spongeous, mixed cortical and spongeous thread profiles, and proximally unthreaded designs have been tested in several studies to determine the most resistant screw thread pattern to pullout forces. ${ }^{[15,16]}$

To measure the pullout strength of a transpedicular screw, a gradual axial force with a constant rate of displacement is applied to a screw inserted into the pedicle of a synthetic or a cadaveric vertebral pedicle. Therefore, it is calculated by measuring the maximum force required for a screw to loose its fixation within the pedicle. ${ }^{[15,17]}$

In the present study, we hypothesized that a standard full cortical pedicle screw design could demonstrate a greater pullout strength compared to other screw designs. We, therefore, aimed to assess the pullout strength of six different transpedicular screw thread profiles under a laboratory setup.

\section{MATERIALS AND METHODS}

\section{Study design}

This study was conducted at the biomechanical laboratory of Dokuz Eylül University Faculty of Medicine between June 2019 and October 2019. To assess the pullout strength in a randomized, biomechanical experimental model, six transpedicular screw with different thread patterns manufactured by (TIPSAN Company AŞ, Izmir, Turkey), were submitted to the pullout strength testing using sheep spine samples. The study protocol was approved by the Dokuz Eylül University, Faculty of Medicine, Ethics Committee (Approval date: 11/01/2017-2). The study was conducted in accordance with the principles of Care and Use of the Laboratory Animals and the animal rights were protected.

Tests were conducted in the biomechanical laboratory of the institution using the axial compression traction testing machine (AG-I $10 \mathrm{kN}$, Shimadzu Shikenki Engineering Co., Ltd, Shimadzu, Japan). The pedicle screw was inserted through the sheep lumbar L3 right pedicle. While the neck of the screw rests upon the head of the pedicle, the head of the screw exits from a hole $1.5 \mathrm{~cm}$ in diameter at the middle of a metal block apparatus created to counteract the pullout force created by a threaded metallic rod connected directly to the screw head and to the testing machine directly (Figure 1a).

\section{Specimens and instruments}

Of 58 fresh-frozen male sheep lumbar spines, 36 lumbar spines were harvested and prepared to become eligible for biomechanical testing of pullout strength measurement used in this study. The sheep model was chosen, as it has been documented to be in close size and shape of human vertebrae. ${ }^{[17,18]}$ The mean age of the male sheep was $16 \pm 4.8$ (range, 11 to 26) months. All sheep spine samples were free of gross and radiological pathology. After performing biomechanical tests, the sheep spine samples underwent an indentation test to assess the bone quality at L3 vertebra. There was no statistically significant difference in the bone quality of the sheep vertebral samples. The sheep lumbar spine samples were divided into six groups with six lumbar spines in each group. The lumbar spine segments (L3-L4) were harvested from each specimen. All the soft tissues were cleaned from the spinal segments with care to maintain the interspinous ligament, ligamentum flavum ligament, facet joint capsules, and the intervertebral discs (Figure 1b).

All sheep spine specimens were wrapped in saline-soaked gauzes and stored in double plastic bags at $-20^{\circ} \mathrm{C}$. Under the guidance of fluoroscopy, the right pedicles of L3 vertebrae were instrumented parallel to the upper end plate without penetrating the walls of the pedicle and the anterior cortex of the vertebra. The titanium polyaxial screw heads were seated straight upon the head of the pedicles.

\section{Screws designs}

In this study, six different pedicle screw designs (Figure 2a-f) were manufactured of titanium alloy (Ti6Al4V) to be examined on sheep spine segments. The specifications of the six pedicular screws were 


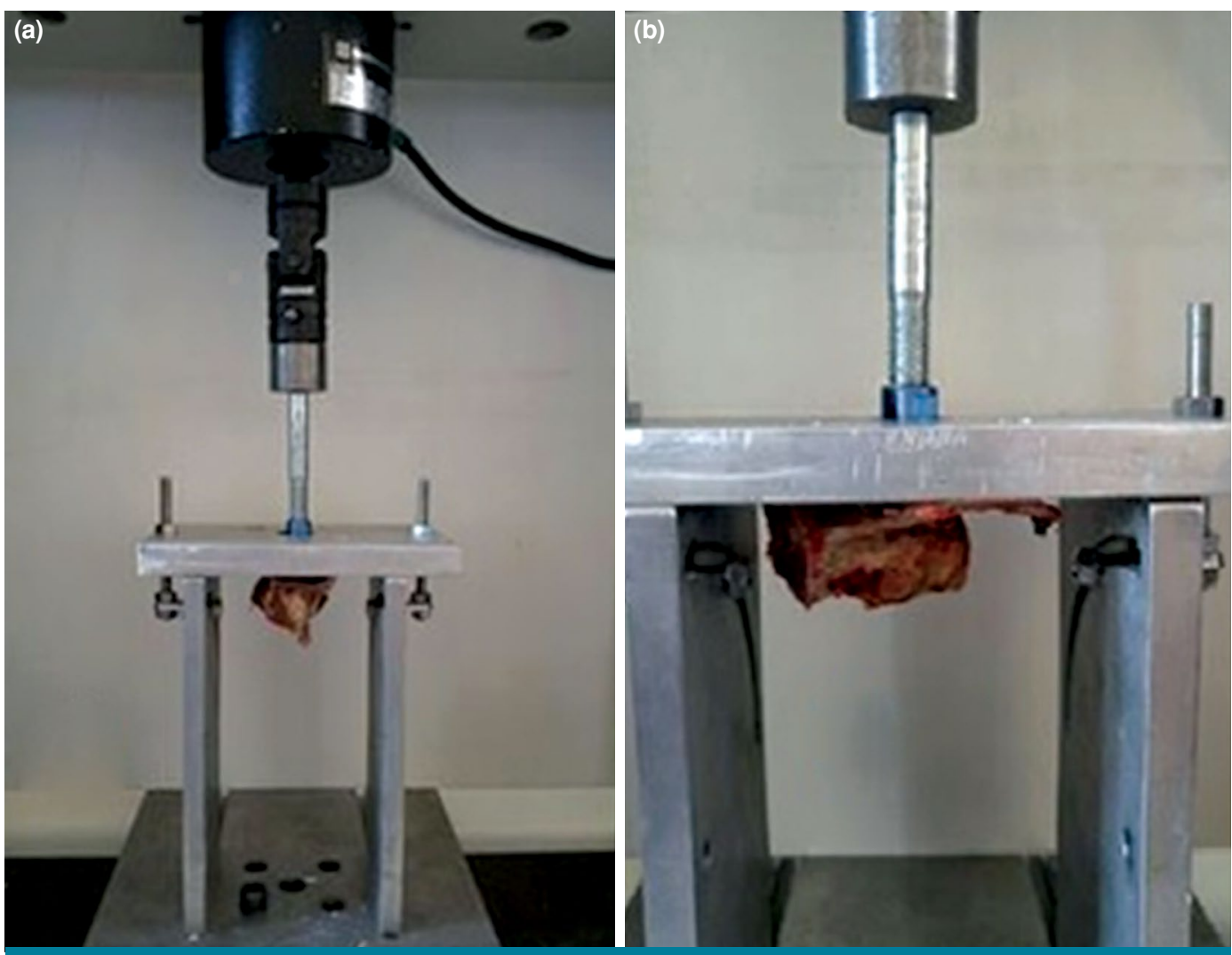

FIGURE 1. (a) Screw head exits from a hole at the middle of a metal block apparatus created to counteract pullout force created by a threaded metallic rod directly connected to screw head and to testing machine. (b) L3- L4 lumbar spine segments cleaned from soft tissue with maintaining ligamentum flavum, facet joint capsules, and intervertebral discs.

(a)

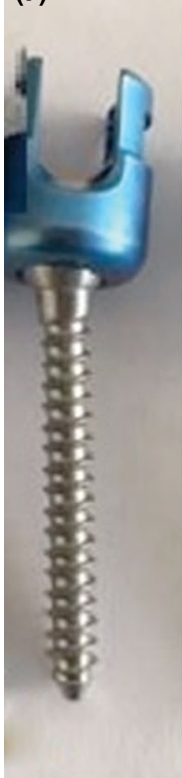

(b)

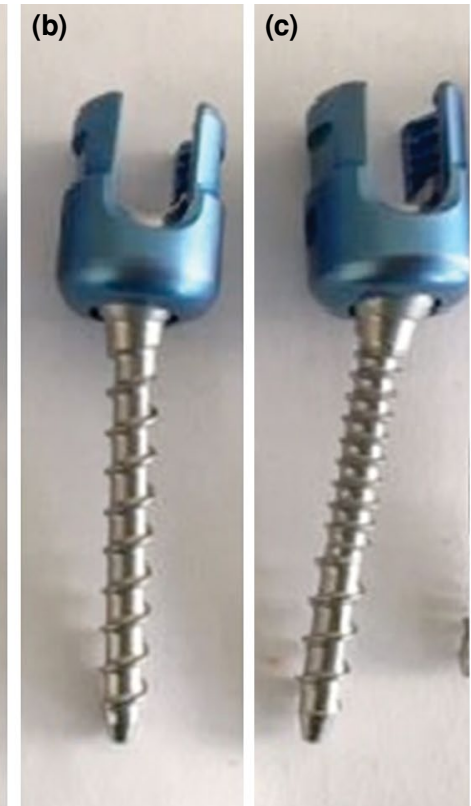

(d)

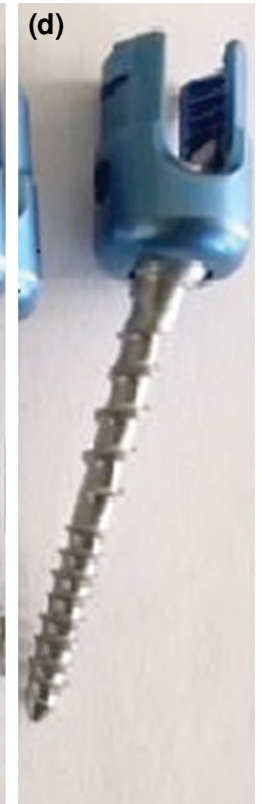

(e)

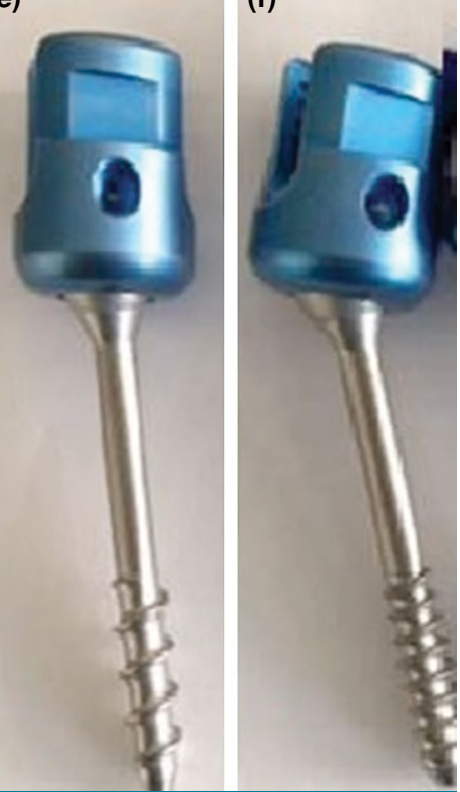

FIGURE 2. Different pedicle screw thread designs. (a) Fully cortical thread design. (b) Fully spongeous thread design. (c) A fully cortical thread in proximal half and a fully spongeous thread in distal half. (d) A fully spongeous thread in proximal half and a fully cortical thread in distal half. (e) Unthreaded proximal half and a fully spongeous threads in distal half. (f) Cortical thread in distal half, whereas proximal half is unthreaded. 
the same in aspect of the outer diameter $(4.5 \mathrm{~mm})$ and the length $(3.5 \mathrm{~mm})$. The sample size was six for each group in each test.

The first screw was a standard fully cortical pedicle screw design (Type A). This screw was assumed to be as the base screw model to compare the results of other screw designs used in this study. The inner diameter was $3.6 \mathrm{~mm}$ on the proximal side and $3 \mathrm{~mm}$ on the distal side. The screw pitch was $2 \mathrm{~mm}$, thread height was $0.9 \mathrm{~mm}$, and the helical angle was $7.8^{\circ}$ (Figure 3a).

The second screw was a fully spongeous thread screw design (Type B). The inner diameter was $3.6 \mathrm{~mm}$ on the proximal side and $3 \mathrm{~mm}$ on the distal side. The screw pitch was $4 \mathrm{~mm}$, thread height was $1.1 \mathrm{~mm}$, and the helical angle was $11.1^{\circ}$ (Figure $3 \mathrm{~b}$ ). The third screw was a mixed thread design, with a fully cortical thread in the proximal half and a fully spongeous thread in the distal half (Type C). The fourth screw was a mixed thread design, with a fully spongeous thread in the proximal half and a fully

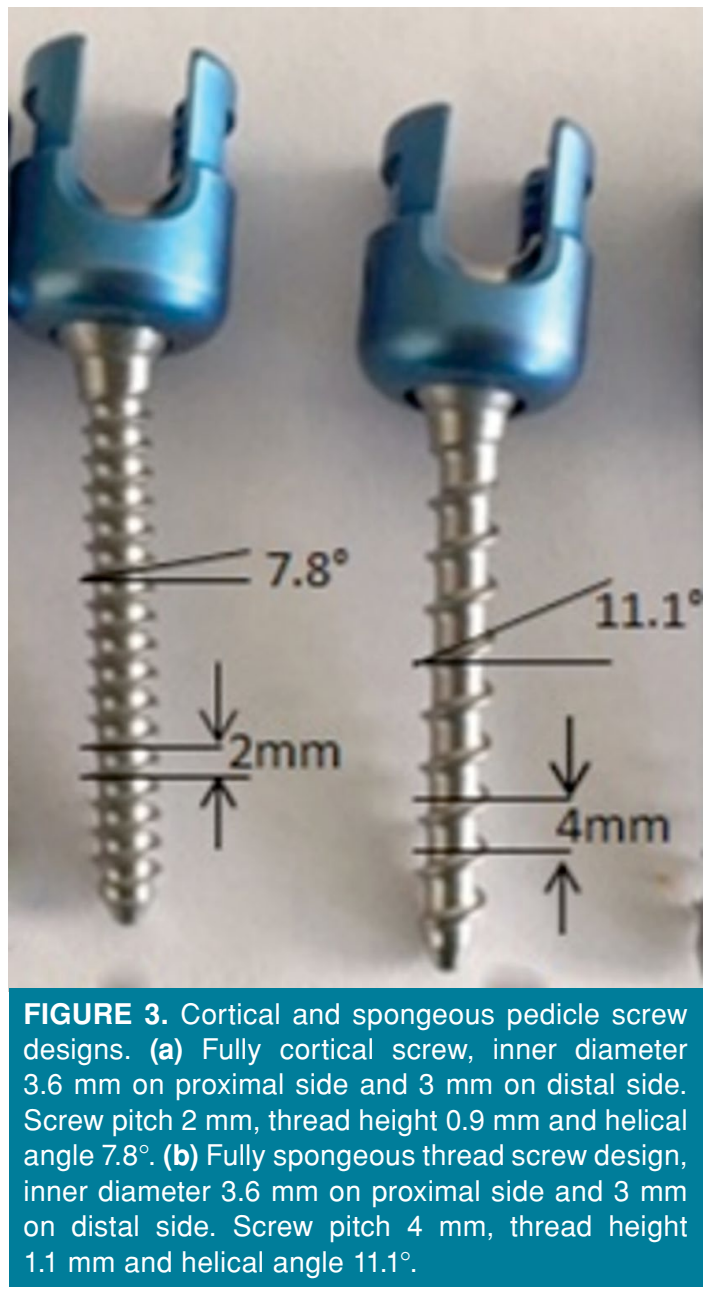

cortical thread in the distal half (Type D). The fifth screw was composed of an unthreaded proximal half and a fully spongeous thread in the distal half (Type E). The sixth screw was designed with cortical thread in the distal half, whereas the proximal half was unthreaded (Type F).

Biomechanical examination was conducted using the axial compression testing machine (AG-I $10 \mathrm{kN}$, Shimadzu Shikenki Engineering Co., Ltd, Shimadzu, Japan) at a pullout rate of $1 \mathrm{~mm} / \mathrm{min}$ traction speed. Each screw was tested six times, and the average pullout strength for each screw type was calculated.

\section{Statistical analysis}

Statistical analysis was performed using the SPSS version 15.0 software (SPSS Inc., Chicago, IL, USA). Descriptive data were expressed in mean \pm standard deviation (SD) or median (min-max), where applicable. For statistical analysis the Mann Whitney U test was conducted. The Mann-Whitney $U$ test was used to compare between study group results. A $p$ value of $<0.05$ was considered statistically significant.

\section{RESULTS}

Type A screw was assumed to be the base screw model to compare the results of other screw designs. The mean values of the pullout strength of the groups A, B, C, D, E, and F were $1112 \pm 7.52 \mathrm{~N}$, $986 \pm 8.34 \mathrm{~N}, 646 \pm 3.88 \mathrm{~N}, 676 \pm 7.16 \mathrm{~N}, 609 \pm 9.52 \mathrm{~N}$, and $769 \pm 6.49 \mathrm{~N}$, respectively (Figure 4).

There was a statistically significant difference between the screw groups A and B, C, D, E and

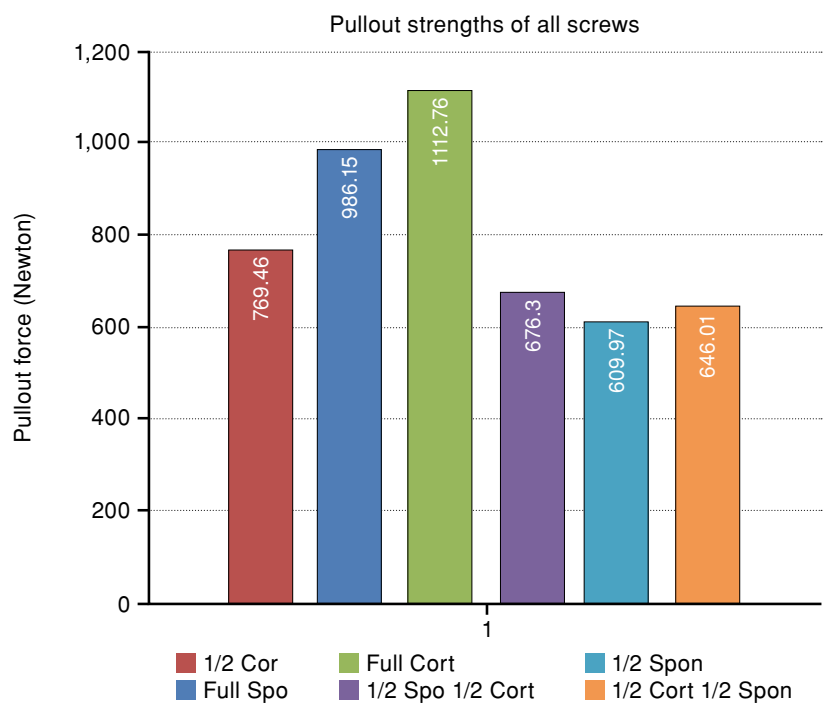

FIGURE 4. Average values of pullout strength of groups $A$, $\mathrm{B}, \mathrm{C}, \mathrm{D}, \mathrm{E}$, and $\mathrm{F}$. 
$\mathrm{F}(\mathrm{p}=0.036, \mathrm{p}=0.028, \mathrm{p}=0.04, \mathrm{p}=0.039$, and $\mathrm{p}=0.046$, respectively). A statistically significant difference was observed between the groups $B$ versus $C$ and $E(p=0.037$ and $p=0.021$, respectively). There was no statistically significant difference between the groups $B$ versus $D$ and $F(p=0.35$ and $p=0.61$, respectively).

Although the fully threaded cortical and spongeous pedicular screws type A and B demonstrated the highest pullout strength among other screw patterns, the fully threaded cortical pedicular screw design type (A) exhibited the strongest bone grasp, compared to other designs with a statistically significant pullout strength, compared to the other five pedicular screw patterns.

\section{DISCUSSION}

In the present study, we examined the pullout strength of six different pedicle screw thread patterns. The most important finding of this study is that fully threaded cortical pedicle screw design was proven to provide a higher pullout strength, compared to other screw designs. ${ }^{[19]}$

Since transpedicular screws ensure a threedimensional stability over the spine segment motion, they have been considered the gold-standard interventional method for several diseases including spinal deformities, degenerative diseases, tumors, and vertebral fractures. ${ }^{[20,21]}$ Screw pullout is a very common problem encountered by surgeons in clinical follow-up. Several studies have demonstrated loosening of transpedicular screws in 0.8 to $11 \%$ of patients. ${ }^{[14,15,21]}$

Weinstein et al. ${ }^{[4]}$ reported that the transpedicular fixation stability depended on the pedicle isthmus by $60 \%$, on the vertebral body core by 15 to $20 \%$, and on the vertebral body anterior cortex penetration by 20 to $25 \%$. However, information related to the thread design effect on the holding strength of a pedicle screw within the pedicle isthmus has not been provided in detail. Several reports have demonstrated that pedicle screw anchoring strength is mainly associated with screw pitch, thread profile, screw shape, and screw diameter. ${ }^{[15,16]}$ The ability of anchoring of a screw-threaded shank emerges from the shearing cut of the engulfed bone chips along the cylindrical surface created by the thread tips. Meanwhile, according to different studies, the greater diameter of the unthreaded shank may squeeze the surrounding bone onto the peripheral cortex walls of a predrilled hole, which in term increases the frictional resistance and, thus, the grasping power of the inserted screw. ${ }^{[16-18,20]}$ Researchers continuously keep parameters design changing in an attempt to obtain the most suitable screw design which may offer the optimal pullout strength to minimize pedicular screw pullout failure as much as possible. ${ }^{[20]}$

In the current study, one the main objectives was to research the holding power of different screw thread profile configurations on the bone-screw construct. The length and the type of the threaded portion were different for the six pedicle screws. Our results demonstrated that, in healthy sheep vertebrae, pedicle screw with a fully threaded cortical design (Type A), had the strongest pullout power, compared to the other pedicle screw designs. The strength of type (A) fully cortical screw design may be owed to the low-pitched thread design which allows a strong anchor to the compact bone of the pedicle and the spongeous bone of the corpus of vertebra.

On the other hand, the result of this study is inconsistent with previous reports. Classical transpedicular screws are designed to be cylindrical in shape with a spongeous single-thread profile. ${ }^{[21-23]}$ Few studies showed that pedicle screws with proximal unthreaded profile could decrease the stress-concentrated effect, thereby reducing the risk of breakage of the screw within the pedicle isthmus. Furthermore, a greater diameter of the unthreaded shank was proposed to squeeze the surrounding bone onto the cortical wall of the predrilled hole, thereby increasing the frictional resistance and the grasping power of the inserted screw. ${ }^{[21-24]}$ However, in this study, the stronger anchoring power of type A design was attributed to the increased embedding compact bone chips of the pedicle isthmus within the screw thread. In addition, the contact of cortical screw threads with low pitches with the surrounding bone allowed progressive tightening of the screw-bone interface with each turn of the screw during insertion, compared to the wide pitched full threaded spongeous screw and proximally unthreaded screw designs.

Of note, as in all biomechanical studies, this study has certain limitations. We were only able to assess the different pedicle screw models on sheep lumbar spines, due to the lack of human spine cadavers. The sheep spine model is still different. Additionally, our biomechanical test was unidirectional and only axial traction was applied. However, in real-life setting, pedicle screws are exposed to multidirectional cyclic pullout axial and vertical forces. Therefore, for a more accurate investigation, the pullout strength of the researched screw models should be investigated on cadaveric 
bone in a multidirectional pullout force pattern in future studies.

In conclusion, fully threaded cortical pedicle screw design has been proven to provide a higher pullout strength, compared to other screw designs. Nonetheless, further studies should be conducted in a multidirectional pullout force pattern on human spine cadavers to assess the six screw thread designs in a closer real-life setting simulation model.

\section{Declaration of conflicting interests}

The authors declared no conflicts of interest with respect to the authorship and/or publication of this article.

\section{Funding}

The authors received no financial support for the research and/or authorship of this article.

\section{REFERENCES}

1. Atik OŞ, Sezgin EA, Tepedelenlioğlu HE. The role of biomarkers in osteoarthritis and osteoporosis for early diagnosis and monitoring prognosis. Eklem Hastalik Cerrahisi 2019;30:175-6.

2. Siminoski K, Warshawski RS, Jen H, Lee KC. The accuracy of clinical kyphosis examination for detection of thoracic vertebral fractures: comparison of direct and indirect kyphosis measures. J Musculoskelet Neuronal Interact 2011;11:249-56.

3. $\mathrm{Hu}$ SS. Internal fixation in the osteoporotic spine. Spine (Phila Pa 1976) 1997;22(24 Suppl):43S-48S.

4. Weinstein JN, Rydevik BL, Rauschning W. Anatomic and technical considerations of pedicle screw fixation. Clin Orthop Relat Res 1992;(284):34-46.

5. Heini PF. The current treatment--a survey of osteoporotic fracture treatment. Osteoporotic spine fractures: the spine surgeon's perspective. Osteoporos Int 2005;16 Suppl 2:S85-92.

6. King D. Internal fixation for lumbosacral fusion. J Bone Joint Surg [Am] 1948;30A:560-5.

7. Boucher HH. A method of spinal fusion. J Bone Joint Surg [Br] 1959;41:248-59.

8. Cotrel Y, Dubousset J, Guillaumat M. New universal instrumentation in spinal surgery. Clin Orthop Relat Res 1988;227:10-23.

9. Chen LH, Tai CL, Lai PL, Lee DM, Tsai TT, Fu TS, et al. Pullout strength for cannulated pedicle screws with bone cement augmentation in severely osteoporotic bone: influences of radial hole and pilot hole tapping. Clin Biomech (Bristol, Avon) 2009;24:613-8.

10. Lin LC, Chen HH, Sun SP. A biomechanical study of the cortex-anchorage vertebral screw. Clin Biomech (Bristol, Avon) 2003;18:S25-32.
11. Paré PE, Chappuis JL, Rampersaud R, Agarwala AO, Perra JH, Erkan S, et al. Biomechanical evaluation of a novel fenestrated pedicle screw augmented with bone cement in osteoporotic spines. Spine (Phila Pa 1976) 2011;36:E1210-4.

12. Taniwaki $Y$, Takemasa $R$, Tani T, Mizobuchi $H$, Yamamoto H. Enhancement of pedicle screw stability using calcium phosphate cement in osteoporotic vertebrae: in vivo biomechanical study. J Orthop Sci 2003;8:408-14.

13. Santoni BG, Hynes RA, McGilvray KC, Rodriguez-Canessa G, Lyons AS, Henson MA, et al. Cortical bone trajectory for lumbar pedicle screws. Spine J 2009;9:366-73.

14. Mehta H, Santos E, Ledonio C, Sembrano J, Ellingson A, Pare $\mathrm{P}$, et al. Biomechanical analysis of pedicle screw thread differential design in an osteoporotic cadaver model. Clin Biomech (Bristol, Avon) 2012;27:234-40.

15. Weiser L, Sehmisch S, Lehmann W, Viezens L. Techniken zur Steigerung der Pedikelschraubenstabilität im osteoporotischen Knochen [Techniques to increase pedicle screw stability in osteoporotic vertebrae]. Oper Orthop Traumatol 2019;31:284-92.

16. Tsai WC, Chen PQ, Lu TW, Wu SS, Shih KS, Lin SC. Comparison and prediction of pullout strength of conical and cylindrical pedicle screws within synthetic bone. BMC Musculoskelet Disord 2009;10:44.

17. Karakaşlı A, Sekik E, Karaarslan A, Kızmazoğlu C, Havıtçıŏlu H. Are pedicular screws and lateral hook screws more resistant against pullout than conventional spinal hooks and screws in terminal vertebral segment fixation? Eklem Hastalik Cerrahisi 2016;27:22-8.

18. Acar N. Behavior of Injured Lamina in Lumbar Burst Fractures during Reduction Maneuvers: A Biomechanical Study. Asian Spine J 2017;11:507-12.

19. Atik OŞ. What are the expectations of an editor from a scientific article? Jt Dis Relat Surg 2020;31:597-8.

20. Varghese V, Krishnan V, Kumar GS. Comparison of pullout strength of pedicle screws following revision using larger diameter screws. Med Eng Phys 2019;74:180-5.

21. Tsuang FY, Chen CH, Wu LC, Kuo YJ, Lin SC, Chiang CJ. Biomechanical arrangement of threaded and unthreaded portions providing holding power of transpedicular screw fixation. Clin Biomech (Bristol, Avon) 2016;39:71-6.

22. Smit TH. The use of a quadruped as an in vivo model for the study of the spine - biomechanical considerations. Eur Spine J 2002;11:137-44.

23. Myers BS, Belmont PJ Jr, Richardson WJ, Yu JR, Harper KD, Nightingale RW. The role of imaging and in situ biomechanical testing in assessing pedicle screw pull-out strength. Spine (Phila Pa 1976) 1996;21:1962-8.

24. Hsu CC, Chao CK, Wang JL, Hou SM, Tsai YT, Lin J. Increase of pullout strength of spinal pedicle screws with conical core: biomechanical tests and finite element analyses. J Orthop Res 2005;23:788-94. 